\title{
Better knowledge with more gauges? Investigation of the spatiotemporal characteristics of precipitation variations over the Greater Beijing Region
}

Article

Accepted Version

Yang, W.-Y., Li, Z., Sun, T. and Ni, G.-H. (2016) Better knowledge with more gauges? Investigation of the spatiotemporal characteristics of precipitation variations over the Greater Beijing Region. International Journal of

Climatology, 36 (10). pp. 3607-3619. ISSN 0899-8418 doi: https://doi.org/10.1002/joc.4579 Available at https://centaur.reading.ac.uk/71093/

It is advisable to refer to the publisher's version if you intend to cite from the work. See Guidance on citing.

To link to this article DOI: http://dx.doi.org/10.1002/joc.4579

Publisher: John Wiley \& Sons

All outputs in CentAUR are protected by Intellectual Property Rights law, including copyright law. Copyright and IPR is retained by the creators or other copyright holders. Terms and conditions for use of this material are defined in the End User Agreement. 


\section{www.reading.ac.uk/centaur}

\section{CentAUR}

Central Archive at the University of Reading

Reading's research outputs online 


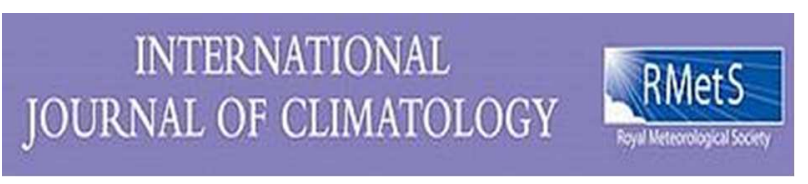

\section{Better knowledge with more gauges? Investigation of the spatiotemporal characteristics of precipitation variations over the Greater Beijing Region}

\begin{tabular}{|r|l|}
\hline Journal: & International Journal of Climatology \\
\hline Manuscript ID & JOC-15-0555.R1 \\
\hline Watey - Manuscript type: & Research Article \\
\hline Complete List of Authors: & $\begin{array}{l}\text { Yang, Wenyu; Tsinghua University, State Key Laboratory of Hydro-Science } \\
\text { and Engineering, Department of Hydraulic Engineering } \\
\text { Li, Zhe; Tsinghua University, State Key Laboratory of Hydro-Science and } \\
\text { Engineering, Department of Hydraulic Engineering } \\
\text { Sun, Ting; Tsinghua University, State Key Laboratory of Hydro-Science and } \\
\text { Engineering, Department of Hydraulic Engineering } \\
\text { Ni, Guangheng; Tsinghua University, State Key Laboratory of Hydro- } \\
\text { Science and Engineering, Department of Hydraulic Engineering }\end{array}$ \\
\hline Keywords: & $\begin{array}{l}\text { Precipitation, Spatiotemporal characteristics, Beijing, Proper measurement } \\
\text { method }\end{array}$ \\
\hline & \\
\hline
\end{tabular}

\section{SCHOLARONE}


Spatiotemporal characteristics of precipitation in Beijing

1

\section{2}

3

4

5

6

7

8

9 15

\section{${ }_{16}^{16}$} 7 18 9

Better knowledge with more gauges? Investigation of the spatiotemporal characteristics of precipitation variations over the

\section{Greater Beijing Region}

Wen-Yu Yang ${ }^{1}$, Zhe $\mathrm{Li}^{2,1}$, Ting Sun ${ }^{1 *}$, Guang-Heng $\mathrm{Ni}^{1}$

1) State Key Laboratory of Hydro-Science and Engineering, Department of Hydraulic Engineering, Tsinghua University, Beijing 100084, China

2) Key Laboratory of Water Cycle and Related Land Surface Processes, Institute of Geographical Sciences and Natural Resources Research, Chinese Academy of Sciences, Beijing 100101, China

(1)

* Corresponding Author: sunting@tsinghua.edu.cn 
Spatiotemporal characteristics of precipitation in Beijing

\section{Abstract}

Using the hourly precipitation observations from 118 gauge stations and a weather radar in the Greater Beijing Region (GBR) during 2008-2012, we investigate the spatiotemporal characteristics of precipitation and discuss the appropriate observational approach for capturing variability of precipitation over this region. In general, the south central and northeastern GBR receives more intense precipitation than other parts. The diurnal cycle of precipitation amount (PA) peaks in the evening and decreases till noon, while precipitation intensity (PI) and precipitation frequency (PF) both have two peaks. The stronger peaks of PI and PF occur in the evening while the weaker ones appear in the early nighttime and in the afternoon. Remarkable spatial heterogeneity also exists in the diurnal patterns of PA, PI and PF over the GBR. Rainstorms extracted from radar data feature in short duration (11.4 hours in average) and highly localized patterns $(4.31-20.58 \mathrm{~km} / 1.85-9.10 \mathrm{~km}$ in major/minor radius direction). The estimated diurnal cycles of PA, PI and PF are found to depend on the gauge density in a sensitivity analysis, where a gauge density ratio of 0.6 (corresponding to 30 gauges in total with a representative area of $239.5 \mathrm{~km}^{2}$ per gauge) is identified as adequate to capture the temporal characteristics of precipitation in the plain area of GBR. However, such gauge density ratio (i.e. 0.6) is incapable for resolving the spatial characteristics of precipitation in GBR. As such, different instruments (e.g. gauge network, weather radar, etc.) and multiple data sources are suggested to be jointly utilized to better capture the characteristics of rainstorms in GBR. 
Spatiotemporal characteristics of precipitation in Beijing

43

44

45

46

47

48

49

50

51

52

53

54

55

56

57

58

59

60

61

62

63

64

Keywords:

Precipitation; Spatiotemporal characteristics; Beijing; Proper measurement method 45

(2)

47

8

9

50

1

53

54

5

56


Spatiotemporal characteristics of precipitation in Beijing

\section{Introduction}

The spatiotemporal characteristics of precipitation hold the key for a better understanding of the physical processes involved in hydrometeorology, especially for those natural hazards linked with precipitation extremes, such as floods and landslides. The variability of precipitation at different scales, either temporally from daily to annual (e.g. Li et al. 2012; Yin et al. 2011; Yu et al. 2015), or spatially from local to global (e.g. Li et al. 2014; Smith and Krajewski 1991), has been extensively investigated. Among a variety of spatiotemporal scales, the precipitation variability at the scale of sub-daily and $\sim 10 \mathrm{~km}$ has been recognized for its critical role in hydrometeorological processes: it not only helps to understand the physical processes of precipitation formation (Dai et al. 1999a, 1999b), but also favors the evaluation of numeric weather prediction (NWP) models in the precipitation forecasting (Wan et al. 2013; Yang and Smith 2006; Yang et al. 2014).

Precipitation variability analysis over contiguous China has been conducted on sub-daily scales in recent years (e.g. Chen et al. 2009; Yin et al. 2009; Yu et al. 2007; Zhou et al. 2008). It is found that the diurnal cycles of precipitation demonstrate distinct regional features over contiguous China, while the causes of the differences have not yet been fully discussed (Yu et al. 2007; Zhou et al. 2008), in particular for the regions with complex topography and land cover (e.g. as discussed in mountainous area by Li et al. 2014, and in urban area by Yin et al. 2011). Moreover, it is found that the precipitation regimes over cities have been remarkably modified by urbanization (Chen et al. 2011; Niyogi et al. 2011; Yang et al. 2013). Considering the 
highly diverse urban surfaces, the severity of storm-induced floods in cities can be worsen by the synergies between precipitation variability and landscape heterogeneity (Yang et al. 2015). However, the spatial variability of precipitation in urban areas is far from being well characterized maybe due to the limitation of the high-resolution data (Westra et al. 2014). As such, there is an urgent need to investigate the precipitation characteristics in cities on finer spatial scales (e.g. $<10 \mathrm{~km})($ Berne et al. 2004).

Beijing, the capital of China with more than 21 million residents, has undergone a rapid urbanization during the past three decades. Beijing is also a topographically complex region, which is surrounded by mountains to its north, northwest, and west and is highly urbanized in its eastern part. Situated at the northwestern part of the North China Plain, Beijing is categorized into temperate monsoon climate zone and characterized by frequent summertime heavy rainfall: the southeast monsoon brings abundant water vapor from the Pacific Ocean; regional mountain-valley circulation combined with land-use and land-cover change (LULC) facilitates local convection and thus leads to the onset of summer rainstorm over Beijing (Yin et al. 2011). Urban storm water is considered as one of the most detrimental hazards in Beijing and shows strong correlation with the summertime rainstorm events (Jia et al. 2012; Zhang et al. 2013). Therefore, the knowledge of regional precipitation characteristics especially that of the summertime rainstorm, has great implications for the mitigation of storm water in Beijing. Li et al. (2008) analyzed the climatic characteristics of diurnal cycles of summer precipitation in Beijing and identified two separate peaks in precipitation 
Spatiotemporal characteristics of precipitation in Beijing

109

110

111

112

113

114

115

116

117

118

119

120

121

122

123

124

125

126

127

129

130

amount and frequency, one in the late afternoon and the other in the early morning.

Also in Beijing, Yin et al. (2011) found that in summer, the precipitation peaks at night over the plains but in the afternoon over the mountains. Although these findings greatly enriched the knowledge of the precipitation characteristics at finer scales in Beijing, it should be noted that they are derived based on hourly records collected from less than 30 stations sparsely located in the Greater Beijing Region (GBR) over an area of 16,410 $\mathrm{km}^{2}$. As suggested by Villarini et al. (2008) and Hofstra et al. (2010), the spatial sampling error tends to be larger as the temporal integration scale becomes smaller. Therefore, the uncertainty associated with temporal characteristics of precipitation retrieved from a low-density gauge network can be large, in particular from networks over highly heterogeneous surfaces, such as the urban areas (Kursinski and Zeng 2006; Gervais et al. 2014; Yang et al. 2013). Besides, the spatial variability of precipitation, especially that of the summertime rainstorm, in the GBR has not yet been thoroughly examined as far as we know.

Motivated by these ideas, we utilize a dense gauge network and a newly available weather radar to investigate the spatiotemporal characteristics of precipitation in GBR by addressing the three specific questions: (1) what is the temporal variability of GBR precipitation at sub-daily scale, which is related to short-duration summer rainstorms, (2) what is the spatial characteristics of precipitation on the meso-gamma scale (i.e. < $20 \mathrm{~km}$ ), focusing on the localized summer rainstorm processes over the GBR, and (3) what is the appropriate approach to monitor the GBR precipitation in the context of these variability characterized at sub-daily and meso-gamma scales? 
Spatiotemporal characteristics of precipitation in Beijing

131

132

133

134

135

In this paper, we start by describing the data and methodology used for the analysis in section 2. Then, we investigate the spatiotemporal characteristics of precipitation in the GBR in section 3: with data from dense gauge network and weather radar, the general spatial pattern is first revisited, while following two parts focus on quantifying sub-daily temporal variations as well as localized spatial pattern of summer rainstorms. Based on these quantitative analysis results, in section 4 we further discuss the impacts of different observational scenarios on the final retrieved characteristics of the diurnal cycle and the summer rainstorm for precipitation in the GBR, prior to final concluding remarks given in section 5 .

\section{Data and methodology}

In this study, we use hourly observations collected from a dense gauge network and a weather radar that are both located in the GBR for the analysis of precipitation characteristics. The gauge network consists of 118 tipping-bucket gauges (their locations are shown in Figure 1) and has been continuously running since 2008 in the charge of the Beijing Water Affairs Bureau. The dataset based on this gauge network is comprised with hourly precipitation records from 2008 to 2012 and has been subject to strict data quality control procedures (Yang et al. 2014). The Da Xing weather radar (an S-band Doppler radar, and its location is denoted by the red triangle in Figure 1) installed by China Meteorological Administration (CMA) is operated at nine elevation angles ranging from $0.5^{\circ}$ to $19.5^{\circ}$ every 6 minutes with a maximum range of $460 \mathrm{~km}$. The range resolution for this radar is $1 \mathrm{~km}$ while the azimuth 
Spatiotemporal characteristics of precipitation in Beijing

153

154

resolution is $1^{\circ}$, and the radar data consists of reflectivity observations from 2008 to 2010. In this study, the radar-based dataset is first resampled into $1 \mathrm{~km}$ gridded hourly data for the following analysis. We note that in this study the radar-based dataset is only used for the spatial pattern analysis rather than the quantitative estimation of rainfall so that we adopt a simple but the most general reflectivity-rainfall relationship ( $Z=300 R^{1.4}, Z$ for reflectivity and $R$ for rainfall intensity). We apply this conversion relationship to get a quantitative precipitation estimate (QPE) data using the reflectivity measured at the third elevation angle $\left(2.4^{\circ}\right)$ by avoiding beam-blockage and ground-clutter.

The general precipitation pattern in the GBR is first investigated based on the gauge data via the five statistics given as follows: annual accumulated precipitation, precipitation occurrence (the rainy hours divided by the total hours of the 5-yr period, $24 \times 1827$ ), hourly and daily maximum precipitation, and the exceedance probabilities of precipitation at various time-scales (Ciach and Krajewski 2006). To illustrate the spatial variations of the exceedance probability curves, rain gauges belonging to different sub-regions with different statistical features of precipitation are selected to calculate regional averaged results (as detailed in section 3.1).

The temporal characteristics analysis follows the methods by Zhuo et al. (2013) and Li et al. (2014). For each hour of a day, precipitation amount (PA) is defined as the accumulated precipitation amount for this hour averaged over the 1827 days of the study period. With consideration of only rainy hours, precipitation intensity (PI) is defined as the accumulated precipitation amount for this hour only divided by the 
Spatiotemporal characteristics of precipitation in Beijing

175

176

177

178

179

180

181

182

183

184

185

186

187

188

189

190

191

192

193

194

195

196

rainy days during the study period. In other words, PA is unconditional average of mean rainfall amount for a particular hour while PI is a conditional average (on rainy days). Precipitation frequency (PF) is calculated as rainy days divided by 1827 days for the hour being considered. In fact, PF also equals to PA divided by PI. It should also be noted that the local standard time (LST, i.e. Beijing Time as UTC +8 hours) is used in this study.

\section{Spatiotemporal characteristics of precipitation}

\subsection{Spatial pattern}

Figure 2 shows the spatial pattern of precipitation in the GBR summarized by the follow statistics "i.e. annual accumulated precipitation, precipitation occurrence, hourly and daily maximum precipitation". The average annual precipitation during 2008-2012 ranges from $202.4 \mathrm{~mm}$ to $719.6 \mathrm{~mm}$ as shown in Figure 2a. Relatively large precipitation amount (larger than $500 \mathrm{~mm}$ ) are mainly observed in the south central and northeastern areas. As shown in Figure $2 \mathrm{~b}$, precipitation occurrence at hourly scale ranges from $1.32 \%$ to $5.29 \%$, and its spatial distribution resembles that of the annual precipitation. Since urban floods are mainly caused by high-intensity precipitation, we also examine the spatial patterns of maximum accumulated precipitation at hourly and daily scales. The hourly maximum precipitation has a similar spatial distribution as the annual precipitation, of which high values appear in the south central and northwestern areas (Figure 2c). However, the high values of maximum daily precipitation are only observed in south central region (Figure $2 \mathrm{~d}$ ). It 
Spatiotemporal characteristics of precipitation in Beijing

197

can thus be inferred that heavy local floods may most likely occur in the south central part of the GBR. Collectively, the results shown in Figure 2 suggest that, precipitation events with high intensity and frequency are mainly concentrated in the south central and northeastern parts of the GBR, leading to the large precipitation amount in the two regions.

To further investigate the spatial distribution of precipitation over the whole GBR, we conduct a Kriging interpolation of annual precipitation amount observed at the 118 gauges. Based on the interpolation results, we have identified three typical regions, of which two regions (labeled as A and B in Figure 3) experience annual precipitation amounts larger than $560 \mathrm{~mm}$ (the $75 \%$ percentile of mean annual precipitation for the whole GBR) whereas the third region (labeled as C in Figure 3) holds an amount less than $420 \mathrm{~mm}$ (the $25 \%$ percentile of mean annual precipitation). We note that, according to the land use classification of the GBR (not shown here), region A is categorized as urban and built-up area. It is also noteworthy that both region A and B identified by the interpolation result generally overlap with the typical precipitation regions found by Yang et al. (2013) via meso-scale WRF simulations: the precipitation regime tends to concentrate in the climatologically downwind region of the urban and built-up area (i.e. region B in this study). In addition, region $\mathrm{C}$ is located in the northwestern mountainous area of the GBR, where the gauges are generally located in the interior valleys of mountains.

Based on this region classification scheme, the region-dependent characteristics of precipitation are further examined in terms of the exceedance probability at the hourly 
and daily scales in Figure 4a and 4b, respectively. Among the sub-regions, region C has the lowest exceedance probability given the same precipitation rate, whereas at hourly scale, region $\mathrm{A}$ and region $\mathrm{B}$ demonstrate similar patterns of exceedance probability when rain rate less than $30 \mathrm{~mm} / \mathrm{h}$, while the exceedance probability of region $A$ is remarkably higher than the others when rain rate higher than $30 \mathrm{~mm} / \mathrm{h}$ (Figure 4a). At daily scale, patterns in region A and region B are similar for all the rain rate (Figure 4b). This analysis of exceedance probabilities demonstrates consistent results as previous studies of precipitation in the GBR: the urban and built-up areas experience more high intensity precipitation events than their surrounding areas (Guo et al. 2006; Yang et al. 2014).

Based on the above results, we also find that the precipitation regime demonstrates significant spatial variability over the GBR. Although exploring the thorough rationale is beyond the scope of this study, the variability can be linked to previous data- and model-driven studies of precipitation regime over urban area by discussing the following aspects. First, precipitation events with higher amount and intensity are more frequently observed in upslope side of the mountain compared with the surrounding regions due to the effects of topography induced local circulation (Clark and Slater 2006; Daly et al. 1994; Li et al. 2014). Yin et al. (2011) confirmed this effect in the GBR by examining the mountain-valley circulation patterns. This finding agrees with our results that higher precipitation is observed along the boundaries between the plain and mountainous area (region B in Figure 3) and less rainfall is observed in the interior mountainous area (region $\mathrm{C}$ in Figure 3). In addition to the 
Spatiotemporal characteristics of precipitation in Beijing

241

242

243

244

245

246

247

248

249

250

251

252

253

254

255

256

257

258

259

260

261

262

effects caused by mountains, cities can modulate the precipitation regime mainly by three mechanisms, including urban heat island effects (Dixon et al. 2003; Oke, 1982), urban canopy effects (Chen et al. 2011; Miao et al. 2011) and urban aerosol effects (Jin et al. 2005; Ntelekoset al. 2009). These urban effects lead to the more precipitation concentrated in the cities and their climatologically downwind areas (Davies et al. 2013). Yang et al. (2013) and Yang et al. (2014) investigated the impact of urbanization on heavy precipitation by WRF simulations, suggesting that the large-scale precipitation patterns are insensitive to the local-scale urban forcings, but the existence of cities does facilitate the formation of convergence zone and provides favorable conditions for deep convection over cities. This simulation-based results show consistency with our observational study that the precipitation events with larger rainfall and higher intensity are more observed in urbanized areas (region A in Figure 3). Overall, the complex precipitation regime over the GBR is shaped by a combination of meso-scale and synoptic scale systems, the regional mountain-valley circulation induced by the topography and possibly urban effects caused by urbanization.

\subsection{Diurnal cycles}

In this section, we investigate the annual averaged diurnal cycles of PA, PI and PF over the GBR from 2008 to 2012. As shown in Figure 5a, PA peaks at 21 LST and then decreases until noon. Compared with PA, two peaks can be observed in the diurnal cycle of PI: the higher peak occurs around 17 LST and the lower one appears at around 02 LST. The difference between diurnal cycles of PA and PI implies the 
Spatiotemporal characteristics of precipitation in Beijing

263

264

265

266

267

268

269

270

271

272

273

274

275

276

277

278

279

280

281

282

283

284

temporal distribution of high intensity rainfall and other rainfall events are different.

The dual-peak pattern is also found in the diurnal cycle of PF, where the higher peak occurs during 20-24 LST whereas the lower one appears during 12-16 LST. The above results indicate that precipitation events in the GBR occur mainly between the afternoon and the early night. It is also shown that precipitation intensity is relatively lower in the afternoon than in the nighttime.

To further investigate the region-dependent features of diurnal cycles, we categorize the gauges according to their sub-region categories so as to obtain sub-regional averaged diurnal cycles, and the diurnal variations of PA, PI, and PF for each sub-region are shown in Figure 6. The diurnal cycles of PA in regions A and B demonstrate similar patterns with an evening peak (during 18-21 LST) as well as a nighttime peak (during 00-03 LST). However, in region C, the only peak of PA is much smaller and shifts to $\sim 16$ LST. As for PI, it is evident that there is an afternoon peak for all the three regions, while another early nighttime peak around 00-03 LST can only be observed in regions A and B. The most significant difference between the urban and built-up areas (i.e. region A) and the mountainous areas (i.e. region C) is observed in the evening and in early nighttime, when the urban heat island effect is recognized as the strongest during a day (Arnfield, 2003). Therefore, it potentially reflects the alternation of local thermal circulation by urban heat island effects, we suspect.

Compared to PA and PI, no significant peak can be observed for PF, and there is no apparent consistence in the occurrence time of the PF peak over different regions. In 
Spatiotemporal characteristics of precipitation in Beijing

region $\mathrm{A}$, there is only one weak peak (approximately 3\%) occurred in the early nighttime. However, region B presents a pattern with two weak peaks: one is similar to region A's nighttime peak and the other occurs in the afternoon, which is possibly caused by local convective precipitation. By contrast, region $\mathrm{C}$ also has an afternoon weak peak (about 2.7\%). All these regimes reflect that the complexity of precipitation system over GBR, which is not only dominated by meso-scale and synoptic scale systems but also influenced by localized controlling factors (orographic effect, urban heat island, etc.).

It has been reported that precipitation over the contiguous China has large diurnal variations with considerable regional features. The northeast $\left(40^{\circ}-50^{\circ} \mathrm{N}, 110^{\circ}-130^{\circ} \mathrm{E}\right)$ China has late afternoon PA maxima (15-18 LST), which can be explained by surface solar heating with concomitant maximum low-level atmospheric instability and moist convection in the afternoon ( $\mathrm{Yu}$ et al. 2007). Although the GBR is situated in the northeast China, its regional diurnal variation of precipitation, as discussed above, distinguishes from the national large-scale pattern. It is suspected that local effects mentioned above (i.e. orographic effect, the urban heat island effect) will accelerate the evening convection, and because the evening and early nighttime PA peaks in part of the GBR, suggesting the GBR potentially has its distinctive diurnal cycles modified by local circulations processes.

Our estimated diurnal cycles are also inconsistent with previous results by Yin et al. (2009) and Yin et al. (2011). Yin et al. (2009) suggested that diurnal patterns of PF and PA were quite similar over the whole north China, except that the afternoon 
maximum of PA was relatively higher. Therefore, Yin et al. (2011) applies the result of Yin et al. (2009) directly to the GBR since the city belongs to north China. However, according to our study, there are obvious differences between the pattern of PA and PF in GBR. Since PA equals to PI multiplied by PF. The differences between the pattern of PA and PF is attribute to the diurnal variation of PI. Compared with the whole north China, local effects may be more significant in the GBR so that there is a peak of PI occurs at night. This new finding indicates that a caution should be paid when we apply the general conclusion drawn over a large region to a small area, especially those are regions with relatively complex topography and land-use.

By conducting an interpolation of gauge-based statistics via the Kriging method, we further investigate the spatial patterns of hourly peaks of PA, PF and PI (denoted as PPA, PPI and PPF, respectively) over the whole GBR. The spatial pattern of PPA is shown in Figure 7a, where large PPA values appear in the northeast and south central regions of GBR while small ones concentrate in the western mountainous area. The largest value $0.15 \mathrm{~mm}$ of PPA is observed in the northeastern downwind region of the GBR urban core, where the storm cells tend to merge as found by Yang et al. (2014). Compared to the spatial pattern of PPA, the larger values of PPI mainly appear in southeastern, northeastern and part of southwestern region whereas the smaller ones are found in the northwestern mountainous area (Figure $7 \mathrm{~b}$ ). The different spatial pattern of PPA and PPI suggests heavy rainfall does not always occur in places where there is large total rainfall. As shown in Figure 7c, PPF holds a different spatial pattern compared to PPA and PPI. The high values of PPF are observed in part of 
Spatiotemporal characteristics of precipitation in Beijing

329

330

331

332

333

southern region, indicating that this region experiences more precipitation events than other parts during the same hours. The polygon pattern of PPF may be attributed to the high variability across the neighboring stations, which in turn implies high resolution measurements are mandatory to resolve the spatial characteristics of precipitation in GBR.

The occurrence time of PPA, PPI and PPF are also presented in Figure 7a, 7b and 7c, respectively, in a clock-style annotation with arrowhead pointing to the time. As is shown in Figure 7a, PPA in the northeastern and south central regions occurs in the evening (18-23 LST) or midnight (02-03 LST), whereas in the northwestern mountainous region it occurs in the afternoon (15-18 LST). Similar as PPA, PPI (shown in Figure 7b) in northeastern and south central regions occurs in the evening (18-23 LST). However, the emerging time of PPI in the northwestern mountainous region does not demonstrate a clear pattern. As for PPF, its occurrence time in different regions presents a diverse pattern and thus cannot be generalized in a straightforward way.

\subsection{Characteristics of summer rainstorm}

Due to the particular importance of summer rainstorm in the GBR, we also examine the characteristics of summer rainstorm in this section. The storm events are first identified with the rain gauge observations as those events with average precipitation of GBR above $20 \mathrm{~mm}$. Thanks to the broad coverage and high spatiotemporal resolution of weather radar, the investigation of the summer rainstorm characteristics is conducted with the estimated precipitation information based on radar observations 
351

352

(details refer to Section 2). It is noted that the observations from the gauge network are not used in the subsequent analysis, due to its limited ability to represent the spatial pattern of precipitation compared with the high resolution data provided by weather radar.

Following the radar-based storm-scale analysis method given by Li et al. (2014), the rainstorm cells are identified and quantified by the following three steps:

1) Rainstorm pixel identification: The rainstorm pixels are determined as those with precipitation intensity larger than the threshold $R_{T}\left(10 \mathrm{~mm} \mathrm{~h}^{-1}\right.$ in this study, or $\sim 39$ dBZ in reflectivity, suggested by China Meteorological Administration, 2012);

2) Rainstorm cell segmentation: the determined rainstorm pixels are clustered by minimizing their distance variance with the isolated ones excluded.

3) Shape approximation: As rainstorm cells can be approximated with an elliptical shape by TITAN algorithm (Dixon and Wiener 1993), all the segmented rainstorm cells are thus approximated with ellipses and the major and minor radii (denoted by $R_{\text {major }}$ and $R_{\text {minor }}$ ) as well as the coverage area (denoted by $A_{R}$ ) can be estimated for subsequent analysis.

With the above 3 -step procedure, 721 rainstorm cells are identified for all the 34 rainstorm events during the 2008 to 2010 (Table 1 ). The life cycle (denoted by $t_{R}$ ) of the rainstorm is $11.4 \mathrm{~h}$ on average. The storm coverage area $A_{R}$ ranges from 25 to $958.8 \mathrm{~km}^{2}$, whereas the major (minor) radius $R_{\text {major }}\left(R_{\text {minor }}\right)$ of estimated ellipses varies within $4.31-20.58 \mathrm{~km}(1.85-9.10 \mathrm{~km})$. The averaged aspect ratio $\left(R_{\text {major }} / R_{\text {minor }}\right)$ is 2.5 , implying the rainstorms cells in the GBR feature long and narrow shapes. It is noted 
Spatiotemporal characteristics of precipitation in Beijing

373

374

375

376

377

378

379

380

381

382

383

384

385

386

387

388

389

390

391

392

393

394

that the smaller rainstorm cells $\left(A_{R}<100 \mathrm{~km}^{2}\right)$ demonstrate narrower shapes than the larger ones.

The intra-event variability of rainstorms which contains more than 10 cells in coverage area and axis length is shown in Figure 8a and 8b, respectively. Significant variability is observed according to both the coverage area (Figure 8a) and axis length (Figure 8b) among most rainstorm events, indicating the complexity in the rainstorm characteristics in the GBR. For instance, the rainstorm cells of the event on July 23, 2009 (the date is highlighted in Figure 8) demonstrate high intra-event variability of the coverage areas (varying from 44 to $13288 \mathrm{~km}^{2}$ ) and the axis length (ranging within $3.6-130.5$ and $1.6-50.2 \mathrm{~km}$ for the major and minor radius, respectively). As discussed above, the intra-event variability, accompanying the inter-event variability discussed above, to some extent demonstrates the challenges in monitoring summertime local rainstorms in the GBR.

The spatial distribution of rainstorms is further examined by the rainstorm cell centers (Figure 9). It is clear that most rainstorm cells are centered in the south central and northeastern parts of the GBR, which is consistent with the spatial pattern of annual rainfall derived from the gauge data (Figure 2). The rainstorm cells are further classified by their cell average intensity (CAI). The five heaviest rainstorm cells $(30<$ $\mathrm{CAI}<40 \mathrm{~mm} \mathrm{~h}^{-1}$ and CAI $>40 \mathrm{~mm} \mathrm{~h}^{-1}$ denoted by orange and red dots in Figure 9, respectively) are centered either on the boundary between the plains and mountains or in the interior mountainous areas, implying the important role of the mountain-valley topography in the formation of severe rainstorms in the GBR (Buytaert et al. 2006, 
395

396

397

398

399

400

401

402

403

404

405

406

407

408

409

410

411

412

413

414

416

415 Setting the density with complete gauges in plain area as the benchmark scenario (i.e.

Daly et al. 1994).

\section{Appropriate observational scenarios for GBR precipitation monitoring}

Since the above results are obtained based on a dense gauge network (118 sites over the GBR) and a weather radar, it is of great interest to know the dependence of such results on the instrumentation. Therefore, in this section, the importance of gauge density and weather radar is assessed by examining the consistency in the observed spatiotemporal variability of precipitation under different instrumentation scenarios over the GBR.

For the temporal variability, it is found the spatial sampling scale has significant impacts on the captured temporal characteristics of precipitation, in particular on the small temporal scales (Villarini et al. 2008, Hofstra et al. 2010). Assuming only limited gauges are available for an analysis as implemented in this study, will those temporal characteristics obtained above still hold? In other words, what is the mandatory minimum gauge density for the GBR to capture the characteristics of diurnal cycles of precipitation adequately? In section 3.2, we have learned that rainfall characteristics distinguishes between the mountainous and plain regions, suggesting the representativeness of gauge density for the two regions should be examined separately. As such, we choose only the plain area (elevation less than $150 \mathrm{~m}$ ) as a test bed to conduct a sensitivity analysis under different gauge density scenarios with the spatially averaged PA, PI and PF as the indicators. 55 sites in total) with density ratio ( $r_{p}$ hereinafter) of 1 , ten gauge density ratios 
417

(provided in Table 2) are designed. To minimize the possible spatial sampling errors, for a given density ratio $r_{p}$, we implement 100 realizations of the random sampling procedure and take the spatially averaged PA, PI and PF obtained by full gauges with $r_{p}=1$ as the benchmark. To quantitatively examine the impact of gauge density on the diurnal cycles estimation in plain area, the hourly mean bias $B_{I}$ and the correlation coefficient $C C$ between the estimated and the benchmark values of a specific indicator $I$ (one of PA, PI and PF) and their corresponding incremental difference $\delta$ under a given $r_{p}$ are calculated as follows:

$$
\begin{gathered}
B_{I}=\frac{1}{24} \sum_{h=1}^{24} \frac{\left|I_{e}(h)-I_{r}(h)\right|}{I_{r}(h)} \\
\mathrm{CC}_{I}=\frac{\operatorname{Cov}\left(I_{e}, I_{r}\right)}{\sigma_{I_{e}} \sigma_{I_{r}}} \\
\delta_{B}=\left|\frac{\Delta B_{r_{p}}}{\Delta r_{p}}\right| \\
\delta_{\mathrm{CC}}=\left|\frac{\Delta \mathrm{CC}_{r_{p}}}{\Delta r_{p}}\right|
\end{gathered}
$$

where $h$ denotes the hour of a day, $\operatorname{Cov}(a, b)$ the covariance function of $a$ and $b, \sigma$ the standard deviation and $\Delta$ the difference operator. The subscripts $e$ and $r$ indicate the estimate and the benchmark, respectively.

Figure 10 shows the hourly mean bias and its corresponding incremental difference of PA, PI and PF with different gauge densities. The bias decreases as the gauge density ratio increases and approaches as low as $5 \%$ at $r_{p}=0.5$. It is noteworthy that as $r_{p}$ is larger than 0.6, the incremental difference values of PA, PI and PF are less than 0.1, implying that the marginal improvement by increasing gauge density becomes limited. 
433

434

435

436

437

438

439

440

441

442

443

444

445

446

447

448

449

450

451

452

453

454

Similar implication is also obtained for the correlation coefficients of PA, PI and PF and their corresponding incremental differences as shown in Figure 11: very little marginal benefits can be obtained when $r_{p}$ becomes larger than 0.6. As such, we identify 0.6 as the representative gauge density ratio (correspond to 30 gauges and a representative area of $239.5 \mathrm{~km}^{2}$ per gauge), with which the characteristics of diurnal cycles of precipitation in the plain area of GBR can be adequately captured.

However, given a gauge density ratio of 0.6 , it can be insufficient to capture the spatial variability of rainstorms under certain scenarios in the GBR, since the coverage area of rainstorm cells ranges from 25 to $958.8 \mathrm{~km}^{2}$ with a median value of $\sim 163 \mathrm{~km}^{2}$, which is much smaller than the representative area per gauge of such a gauge network (i.e. $239.5 \mathrm{~km}^{2}$ ). In other words, the geometric features of some rainstorms can hardly be resolved by a gauge network that satisfies the criteria for capturing temporal variability of precipitation in the GBR. Even under the present-day gauge density, a gauge network still has difficulty in capturing all the local rainstorms that can be resolved by a weather radar. As such, in order to capture the finer spatial variability of precipitation in the GBR, it is necessary to increase the gauge density or to install weather radars. However, on one hand, the refinement of a gauge network is not only costly and but also infeasible under certain conditions (e.g. installment of gauges in densely urbanized area such as central business districts); on the other hand, the remarkable inaccuracy in current radar-based quantitative precipitation estimate (QPE) systems raise high uncertainty in the assessment of quantity-sensitive characteristics of precipitation (such as PA and PI). Therefore, it is recommended that 
Spatiotemporal characteristics of precipitation in Beijing

455

456

457

458

459

460

461

462

463

464

465

466

467

468

469

470

471

472

473

474

475

476

the optimal strategy for GBR is to jointly utilize different instruments and to synthesize multiple data sources, rather than to adopt a "one-solution-fits-all" strategy.

\section{Concluding remarks}

In this study, we investigated the spatiotemporal characteristics of precipitation over the Greater Beijing Region by using a five-year dataset of hourly precipitation collected from a dense gauge network consisting of 118 sites and a three-year dataset of hourly precipitation estimates obtained by an S-band Doppler radar. In addition, we further discussed the impact of gauge density and weather radar on capturing spatiotemporal variability of precipitation in GBR. The major findings are summarized as follows:

1. High spatial variability is observed for precipitation regimes over the GBR as indicated by the selected statistics, including annual accumulated precipitation, precipitation occurrence, hourly and daily maximum precipitation. Large precipitation amount and high intensity are mainly found in the south central and northeastern parts of the GBR, whereas the high values of daily maximum precipitation only appear in the south central part. It is also worth noting that the hourly and daily precipitation amounts in northwestern mountainous area are significantly lower than other parts of the GBR. Besides, analysis of exceedance probabilities at hourly scale reveals that southern urban area experiences more heavy precipitation events compared to its surrounding areas.

2. Three sub-regions can be identified by the gauge-based annual precipitation: 
Spatiotemporal characteristics of precipitation in Beijing

477

478

479

480

481

482

483

484

485

regions $\mathrm{A}$ and $\mathrm{B}$ have annual precipitation more than $560 \mathrm{~mm}$ (the $75 \%$ percentile of mean annual precipitation in GBR), while region $\mathrm{C}$ holds annual precipitation less than $420 \mathrm{~mm}$ (the $25 \%$ percentile of mean annual precipitation in the GBR). Since region A features for its built-up urban surfaces while region $\mathrm{C}$ is categorized as the mountainous area, this region-dependent precipitation regime can be explained by the regional mountain-valley circulation induced by the topography combined with the possible effects by urbanization.

3. The diurnal cycle of PA (precipitation amount) peaks in the evening and decreases till noon, while that of PI and PF presents a dual-peak pattern. PI (precipitation intensity) and PF (precipitation frequency) both have two peaks: the stronger ones of PI and PF both occur in the evening while the weaker ones appear in the early nighttime for PI and in the afternoon for PF, respectively. Remarkable spatial variability also exists in the diurnal cycles over the GBR. For PA and PI, the diurnal cycles of regions A and B peak in the evening (18-21 LST), whereas that of region $\mathrm{C}$ peaks in the afternoon (15-18 LST). As for PF, its peak appears later in region $\mathrm{C}$ than in regions $\mathrm{A}$ and $\mathrm{B}$.

4. Rainstorms in the GBR are characterized by short durations (average $\sim 11.4$ hours) and highly localized patterns $\left(R_{\text {major }}\right.$ and $R_{\text {minor }}$ vary within $4.31-20.58 \mathrm{~km}$ and 1.85-9.10 km, respectively) based on the newly available radar data. The extracted storm centers show that most rainstorms are located in the south central and northeastern part of the GBR. Given the current gauge density in the GBR with the representative coverage area of $136 \mathrm{~km}^{2}$ per gauge, some of the localized 
Spatiotemporal characteristics of precipitation in Beijing

499

500

501

502

503

504

505

506

507

508

509

510

511

512

rainstorms of the GBR cannot be resolved by the gauge network with the present-day density.

5. The observed spatiotemporal variability is shown to be affected by various instrumentation scenarios. By varying the gauge density ratio, it is found that a gauge density ratio of 0.6 (corresponding a representative area of $239.5 \mathrm{~km}^{2}$ per gauge) can adequately capture the characteristics of diurnal cycles using different summary statistics (i.e. PA, PI and PF) in the plain area of GBR. However, even given such a gauge density ratio, the gauge network may be unable to resolve the finer spatial variability associated with the summer rainstorms. Therefore, it is suggested to jointly utilize different instruments (e.g. gauge network, weather radar, etc.) and to synthesize multiple data sources (e.g. ground rainfall records, radar measurements, etc.) in future so as to better monitor and characterize the spatiotemporal variability of precipitation in the GBR. 
Spatiotemporal characteristics of precipitation in Beijing

513

514

515

516

517

518

\section{Acknowledgement}

This work is supported by the National Science Foundation of China under Grant No.

51190092 and 51409147, by China Postdoctoral Science Foundation under Grant No.

2015 T80093 and by the Ministry of Science and Technology of China under Grant

No. 2013DFG72270. We are grateful to the Beijing Water Affairs Bureau and China

Meteorological Administration for the assistance in providing data. 
Spatiotemporal characteristics of precipitation in Beijing

519

520

521

522

523

524

525

526

527

528

529

530

531

532

533

534

535

536

537

538

539

540

\section{Reference:}

Arnfield AJ. 2003. Two decades of urban climate research: a review of turbulence,

exchanges of energy and water, and the urban heat island. International Journal of Climatology 23(1): 1-26.

Berne A, Delrieu G, Creutin J, Obed C. 2004. Temporal and spatial resolution of rainfall measurements required for urban hydrology. Journal of Hydrology 299: $166-179$.

Buytaert W, Celleri R, Willems P, Bievre BD, Wyseure G. 2006. Spatial and temporal rainfall variability in mountainous areas: A case study from the south Ecuadorian Andes. Journal of Hydrology 329: 413-421.

Chen F, Kusaka H, Bornstein R. 2011. The integrated WRF/urban modeling system: Development, evaluation, and applications to urban environmental problems. International Journal of Climatology 31(2): 273-288.

Chen G, Sha W, Iwasaki T. 2009. Diurnal variation of precipitation over southeastern China: Spatial distribution and its seasonality. Journal of Geophysical Research: Atmospheres 114, D13103.

China Meteorological Administration, 2012. <www.cma.gov.cn/2011xzt/ 2012zhuant/20120928_1_1_1_1/2010052703/201212/t20121212_195616.html >.

Ciach GJ, Krajewski WF. 2006. Analysis and modeling of spatial correlation structure in small-scale rainfall in Central Oklahoma. Advances in Water Resources 29: 14501463.

Clark MP, Slater AG. 2006. Probabilistic quantitative precipitation estimation in 
Spatiotemporal characteristics of precipitation in Beijing

541

542

543

544

545

546

547

548

549

550

551

552

553

554

555

556

557

558

559

560

561

562

complex terrain. Journal of Hydrometeorology 7(1): 3-22.

Dai A, Trenberth KE, Karl TR. 1999a. Effects of clouds, soil moisture, precipitation, and water vapor on diurnal temperature range. Journal of Climate 12: 2451-2473.

Dai A, Giorgi F, Trenberth KE. 1999b. Observed and model simulated diurnal cycles of precipitation over the contiguous United States. Journal of Geophysical Research: Atmospheres 104: 6377-6402.

Daly C, Neilson RP, Phillips DL. 1994. A statistical-topographic model for mapping climatological precipitation over mountainous terrain. Journal of Applied Meteorology 33(2): 140-158.

Davies LC, Jakob P, May VV, Kumar, Xie S. 2013. Relationships between the large-scale atmosphere and the small-scale convective state for Darwin, Australia. Journal of Geophysical Research: Atmospheres 118: 11,534-11,545.

Dixon M, Wiener G. 1993. TITAN: Thunderstorm Identification, Tracking, Analysis, and Nowcasting - A radar-based methodology. Journal of Atmospheric and Oceanic Technology 10: 785-797.

Dixon PG, Mote TL, 2003. Patterns and causes of Atlanta's urban heat island-initiated precipitation. Journal of Applied Meteorology and Climatology 42(9): 1273-1284.

Gervais M, Tremblay B, Gyakum J, Atallah E. 2014. Representing extremes in a daily gridded precipitation analysis over the United States: Impacts of station density, resolution, and gridding methods. Journal of Climate 27: 5201-5218,

Guo X, Fu D, Wang J. 2006. Mesoscale convective precipitation system modified by urbanization in Beijing City. Atmospheric Research 82(1-2): 112-126. 
Spatiotemporal characteristics of precipitation in Beijing

563

564

565

566

567

568

569

570

571

572

573

574

575

576

577

578

579

580

581

582

583

584

Hofstra N, New M, McSweeney C. 2010. The influence of interpolation and station network density on the distributions and trends of climate variables in gridded daily data. Climate Dynamics 35: 841-858.

Jia H, Lu Y, Yu SL, Chen Y. 2012. Planning of LID-BMPs for urban runoff control: The case of Beijing Olympic Village. Separation and Purification Technology 84: 112-119.

Jin M, Shepherd JM, King MD. 2005. Urban aerosols and their variations with clouds and rainfall: A case study for New York and Houston. Journal of Geophysical Research: Atmospheres 110: D10S20.

Kursinski AL, Zeng X. 2006. Areal estimation of intensity and frequency of summertime precipitation over a midlatitude region. Geophysical Research Letters 33: L22401.

Li J, Yu RC, Wang JJ. 2008. Diurnal variations of summer precipitation in Beijing. Chinese Science Bulletin 53(12): 1933-1936.

Li M, Yang D, Chen J, Hubbard SS. 2012. Calibration of a distributed flood forecasting model with input uncertainty using a Bayesian framework. Water Resources Research 48: W08510.

Li Z, Yang D, Hong Y, Zhang J. 2014. Characterizing spatiotemporal variations of hourly rainfall by gauge and radar in the mountainous Three Gorges Region. Journal of Applied Meteorology and Climatology 53(4): 873-889.

Miao S, Chen F, Li Q, Fan S. 2011. Impacts of urban processes and urbanization on summer precipitation: A case study of heavy rainfall in Beijing on 1 August 2006. 
Spatiotemporal characteristics of precipitation in Beijing

585

586

587

588

589

590

591

592

593

594

595

596

597

598

599

600

601

602

603

604

605

606

Journal of Applied Meteorology and Climatology 50(4): 806-825.

Niyogi D, Pyle P, Lei M, Arya SP, Kishtawal CM, Shepherd M, Chen F, Wolfe B.

2011. Urban modification of thunderstorms: An observational storm climatology and model case study for the Indianapolis urban region. Journal of Applied Meteorology and Climatology 50(5): 1129-1144.

Ntelekos AA, Smith JA, Donner L, Fast JD, Gustafson Jr WI, Chapman EG, Krajewski WF. 2009. The effects of aerosols on intense convective precipitation in the Northeastern US. Quarterly Journal of the Royal Meteorological Society 135: $1367-1391$.

Oke TR. 1982. The energetic basis of the urban heat island. Quarterly Journal of the Royal Meteorological Society 108(455): 1-24.

Smith JA and Krajewski WF. 1991. Estimation of the mean field bias of radar rainfall estimates. Journal of Climate and Applied Meteorology 30(4): 397-412.

Smith JA, Baeck ML, Villarini G, Welty C, Miller AJ, Krajewski WF. 2012. Analyses of a long-term, high-resolution radar rainfall data set for the Baltimore metropolitan region. Water Resources Research 48(4): W04504,

Villarini G, Mandapaka PV, Krajewski WF, Moore RJ. 2008. Rainfall and sampling uncertainties: A rain gauge perspective. Journal of Geophysical Research: Atmospheres 113: D11102.

Wan H, Rasch PJ, Zhang K, Kazil J, Leung LR. 2013. Numerical issues associated with compensating and competing processes in climate models: an example from ECHAM-HAM. Geoscientific Model Development 6(3): 861-874. 
607

608

609

610

611

612

613

614

615

616

617

618

619

620

621

622

623

624

625

626

627

628

Westra S, Fowler HJ, Evans JP, Alexander LV, Berg P, Johnson F, Kendon EJ,

Lenderink G, Roberts NM. 2014. Future changes to the intensity and frequency of short duration extreme rainfall. Reviews of Geophysics 52: 522-555.

Yang L, Tian F, Smith JA, Hu H. 2014. Urban signatures in the spatial clustering of

summer heavy rainfall events over the Beijing metropolitan region. Journal

of Geophysical Research: Atmospheres 119: 1203-1217.

Yang L, Tian F, Niyogi D. 2015. A need to revisit hydrologic responses to urbanization by incorporating the feedback on spatial rainfall patterns. Urban Climate

12: $128-140$.

Yang P, Ren G, Hou W, Liu W. 2013. Spatial and diurnal characteristics of summer rainfall over Beijing Municipality based on a high - density AWS dataset. International Journal of Climatology 33(13): 2769-2780.

Yang S, Smith EA. 2006. Mechanisms for diurnal variability of global tropical rainfall observed from TRMM. Journal of Climate 19(20): 5190-5226.

Yin S, Chen D, Xie Y. 2009. Diurnal variations of precipitation during the warm season over China. International Journal of Climatology 29(8): 1154-1170.

Yin S, Li W, Chen D, Jeong J, Guo W. 2011. Diurnal variations of summer precipitation in the Beijing area and the possible effect of topography and urbanization. Advances in Atmospheric Sciences 28(4): 725-734.

Yu R, Zhou T, Xiong A, Zhu Y, Li J. 2007. Diurnal variations of summer precipitation over contiguous China. Geophysical Research Letters 34: L01704.

Yu R, Chen H, Sun W. 2015. The definition and characteristics of 
Spatiotemporal characteristics of precipitation in Beijing

629

630

631

632

633

634

635

636

637

638

639 regional-rainfall-events demonstrated by warm season precipitation over the Beijing plain. Journal of Hydrometeorology 16: 396-406.

Zhang DL, Lin Y, Zhao P, Yu X, Wang S, Kang H, Ding Y. 2013. The Beijing extreme rainfall of 21 July 2012: "Right results" but for wrong reasons. Geophysical Research Letters 40: 1426-1431

Zhou T, Yu R, Chen H, Dai A, Pan Y. 2008. Summer precipitation frequency, intensity, and diurnal cycle over China: A comparison of satellite data with rain gauge observations. Journal of Climate 21(16): 3997-4010.

Zhuo H, Zhao P, Zhou T. 2013. Diurnal cycles of summer precipitation in Shandong of eastern China. International Journal of Climatology 34(3): 742-750. 


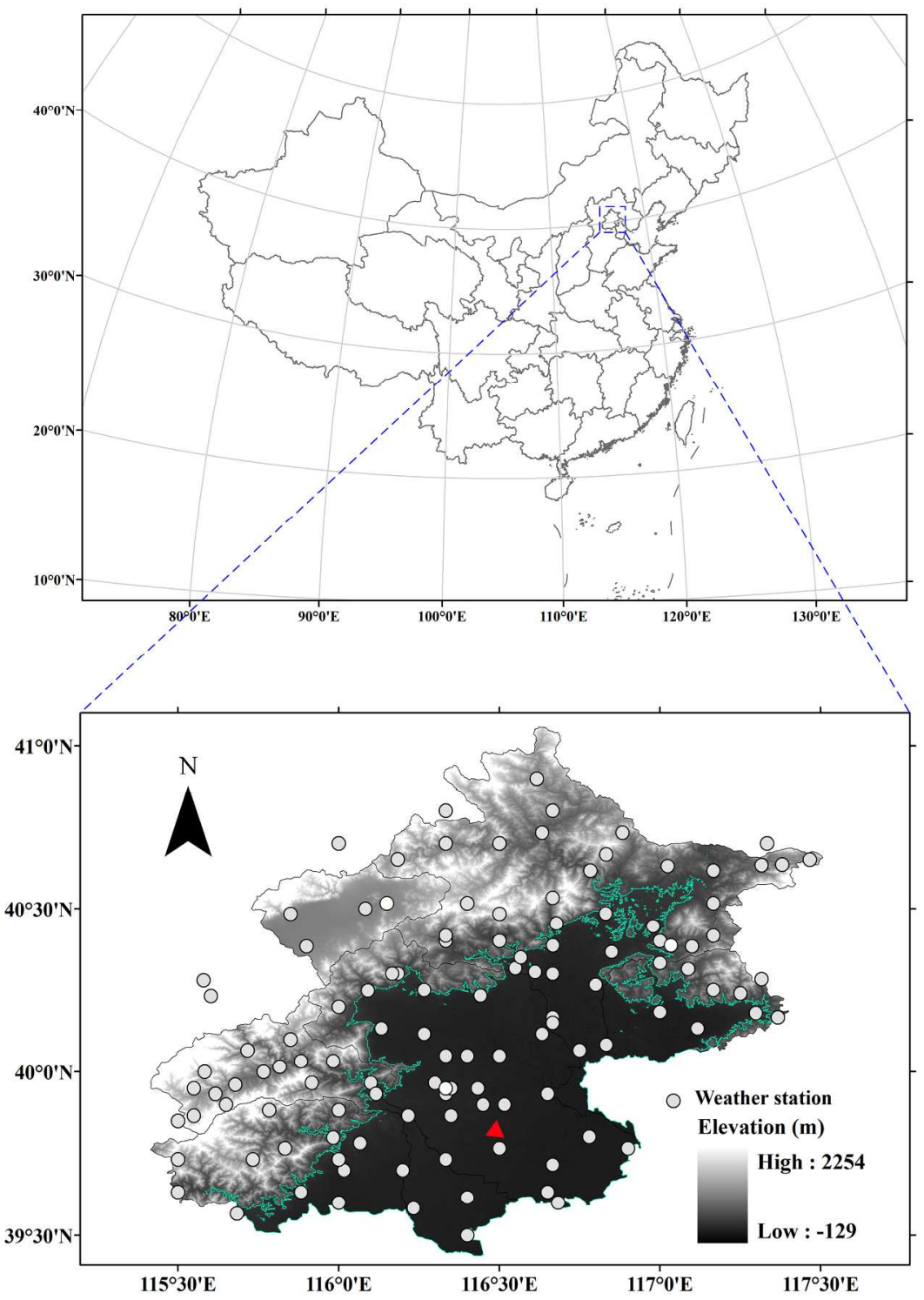

Figure 1 The topography in GBR. Gray dots and the red triangle indicate 118 rain-gauge sites and the Sband Doppler radar, respectively. $200 \times 287 \mathrm{~mm}(300 \times 300$ DPI $)$ 
(a)

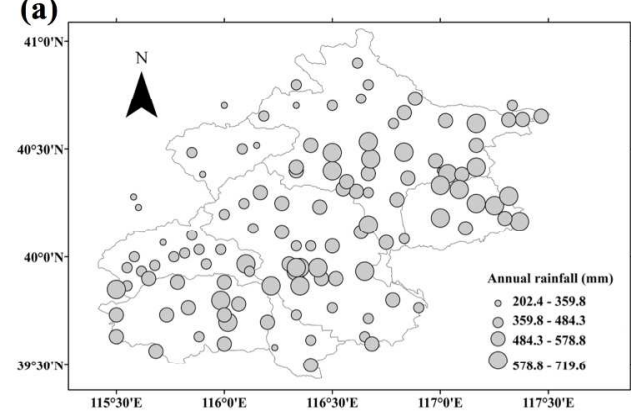

(c)

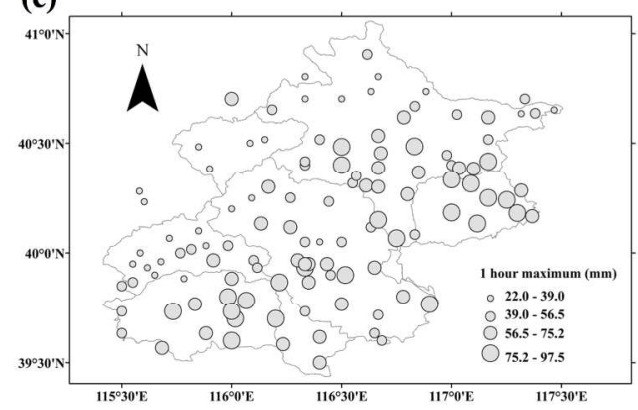

(b)

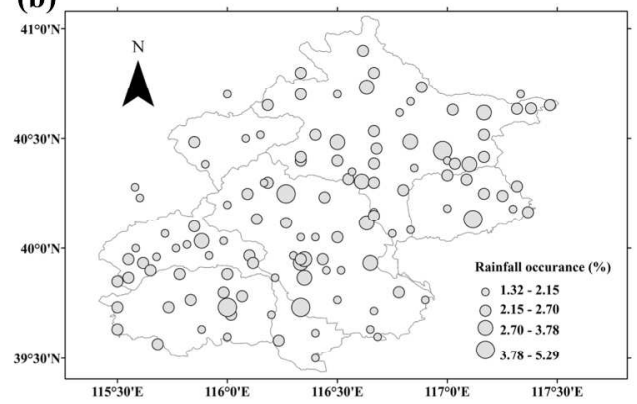

(d)

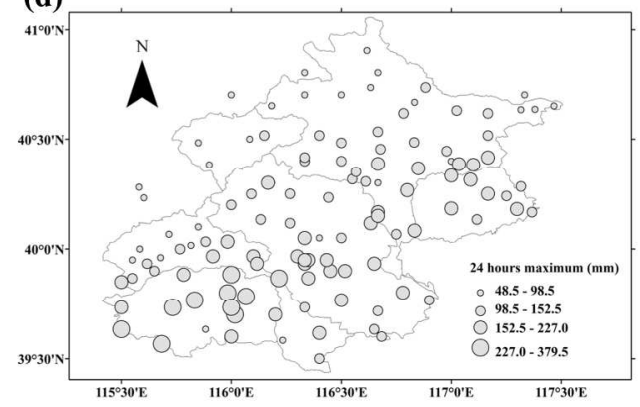

Figure 2 Spatial pattern of precipitation during 2008-2012 in GBR of (a) annual accumulated precipitation $(\mathrm{mm}),(\mathrm{b})$ precipitation occurrence $(\%),(\mathrm{c})$ 1-hour maximum precipitation $(\mathrm{mm})$ and $(\mathrm{d})$ 24-hour maximum precipitation ( $\mathrm{mm})$. $253 \times 179 m m(300 \times 300$ DPI $)$ 


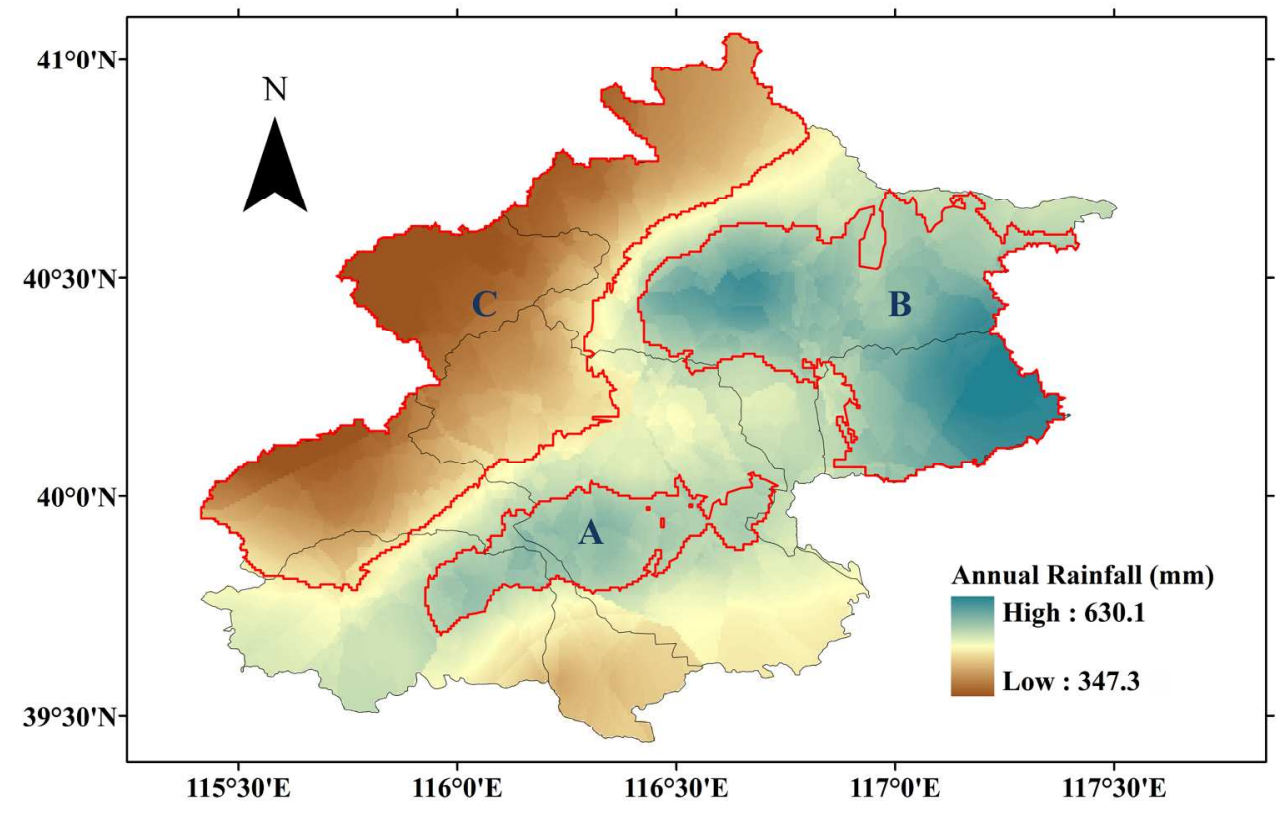

Figure 3 Spatial distributions of annual precipitation and three identified sub-regions. $296 \times 210 \mathrm{~mm}(300 \times 300 \mathrm{DPI})$ 

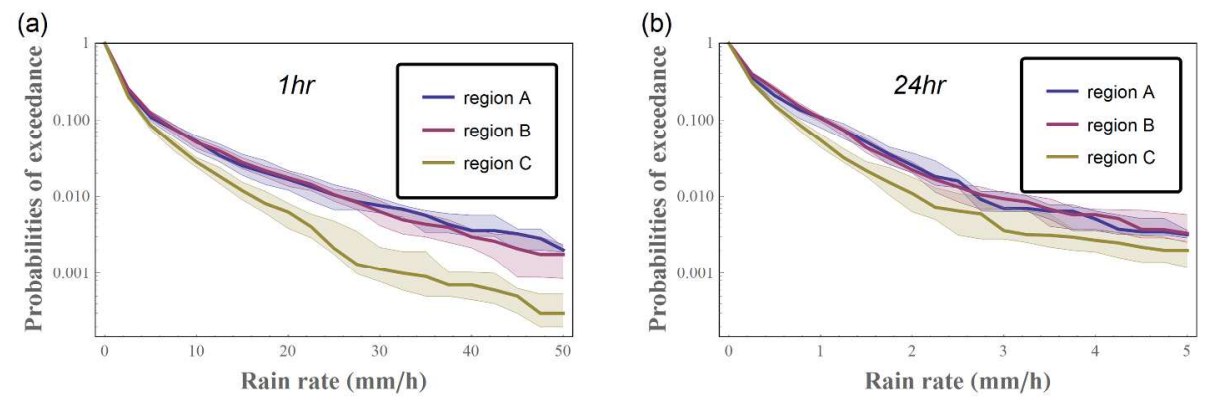

Figure 4 Sub-regional probabilities of exceedance for rain rate within (a) 1-hour and (b) 24-hour during 2008-2012 in GBR, the thick line represents the median value of each sub-region, while the thin line are the lower 25th and upper 75th quartile.

$$
282 \times 86 \mathrm{~mm}(300 \times 300 \text { DPI) }
$$



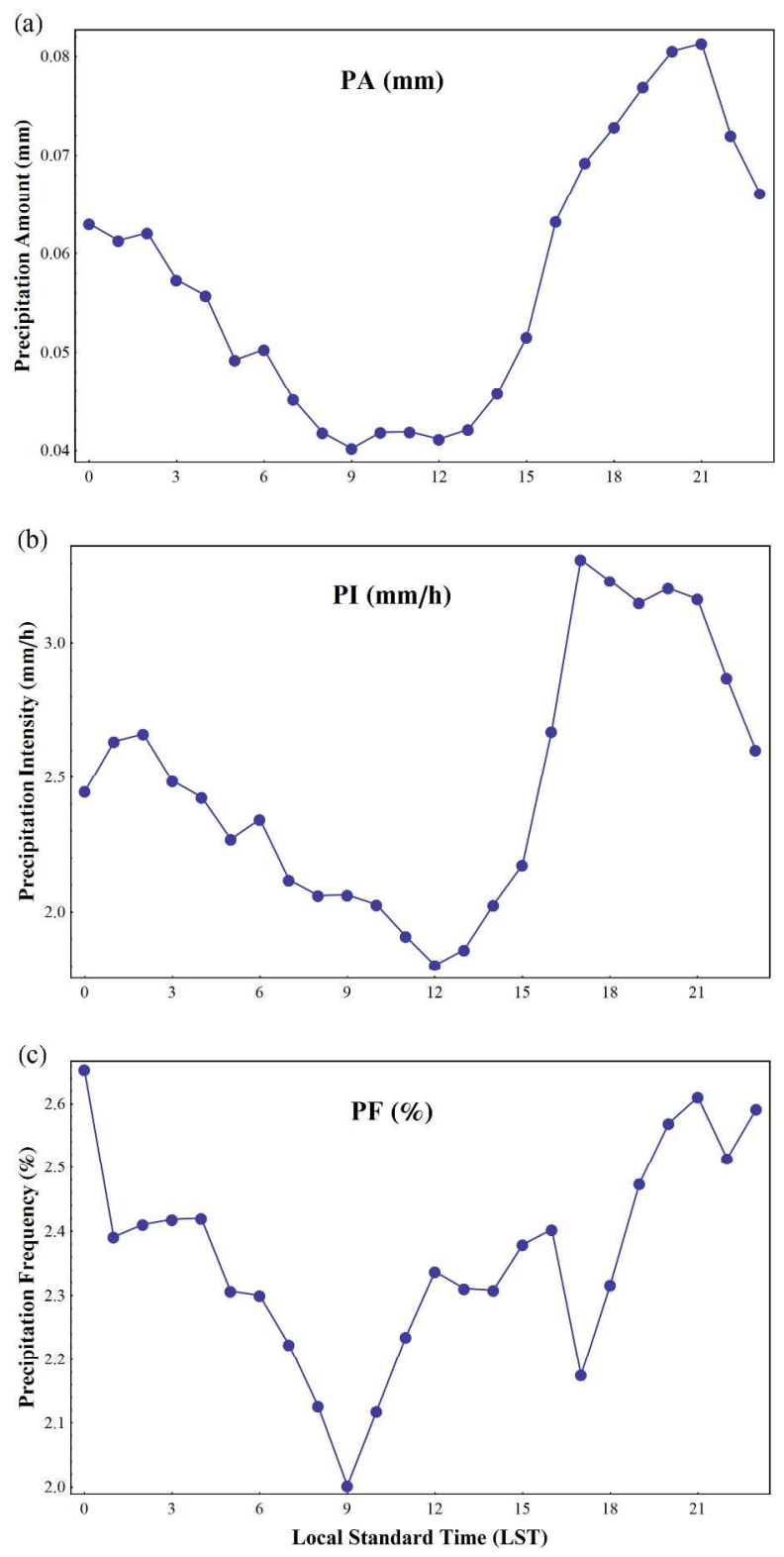

Figure 5 Regional averaged diurnal cycle of (a) PA (mm), (b) PI (mm hr-1) and (c) PF (\%) in GBR. $176 \times 327 \mathrm{~mm}(300 \times 300 \mathrm{DPI})$ 

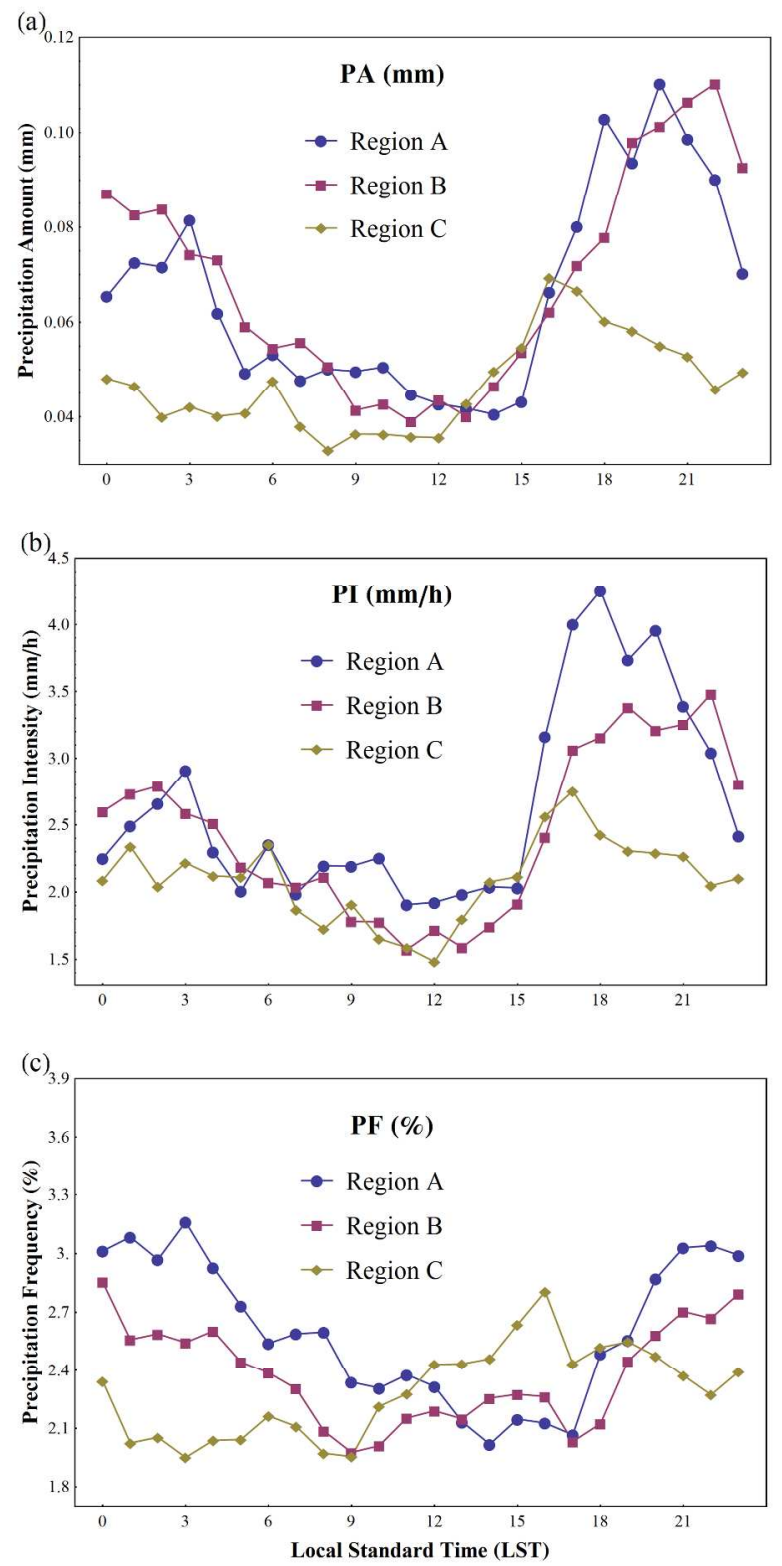

Figure 6 Sub-regional averaged diurnal cycle of (a) PA (mm), (b) PI (mm hr-1) and (c) PF (\%) in GBR. $176 \times 327 \mathrm{~mm}(300 \times 300 \mathrm{DPI})$ 

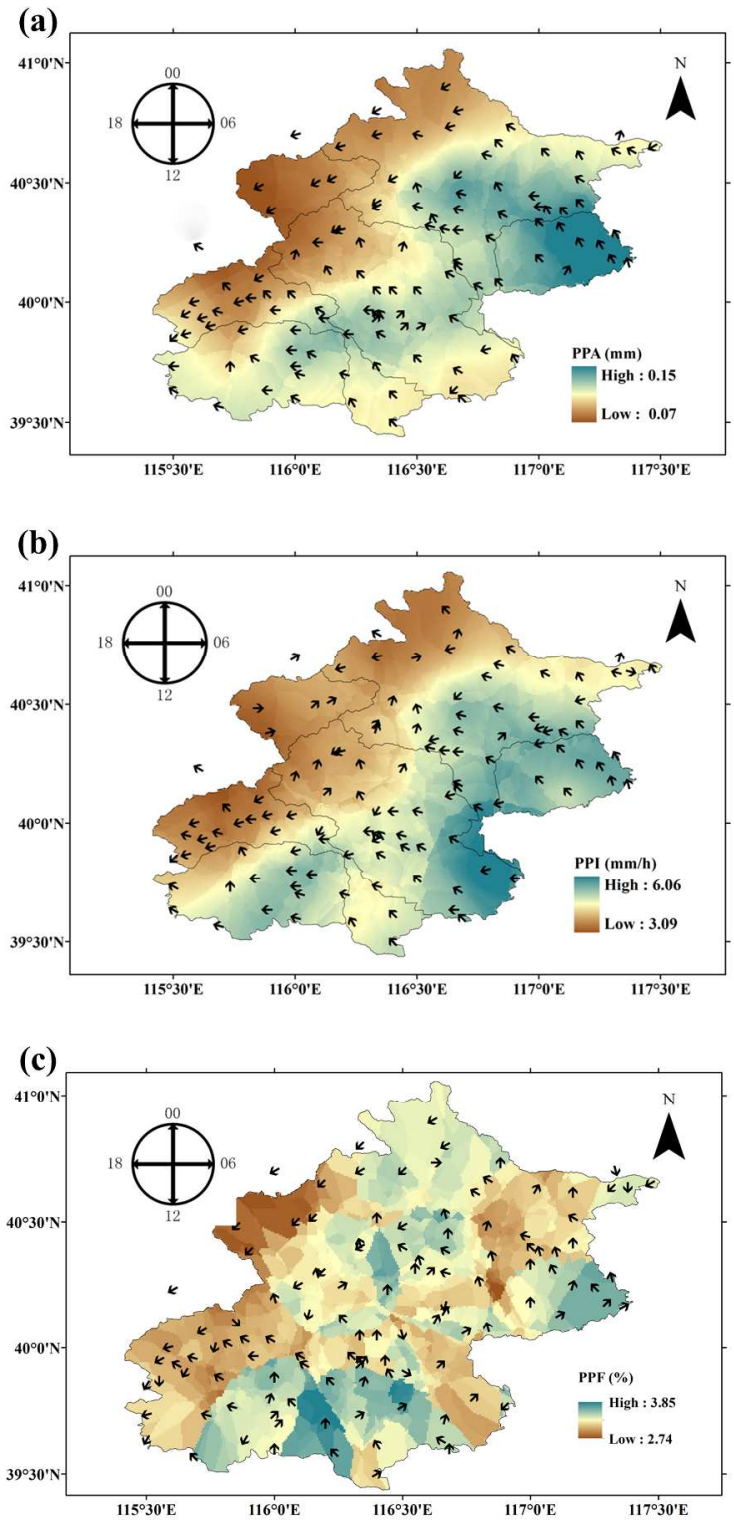

Figure 7 Spatial distributions of (a) PPA (mm), (b) PPI (mm hr-1), (c) PPF (\%) (The background colors indicate the magnitude of PPA, PPI and PPF values and the arrow pointer on a circular clock dial indicates the peak time).

$138 \times 287 \mathrm{~mm}(300 \times 300 \mathrm{DPI})$ 

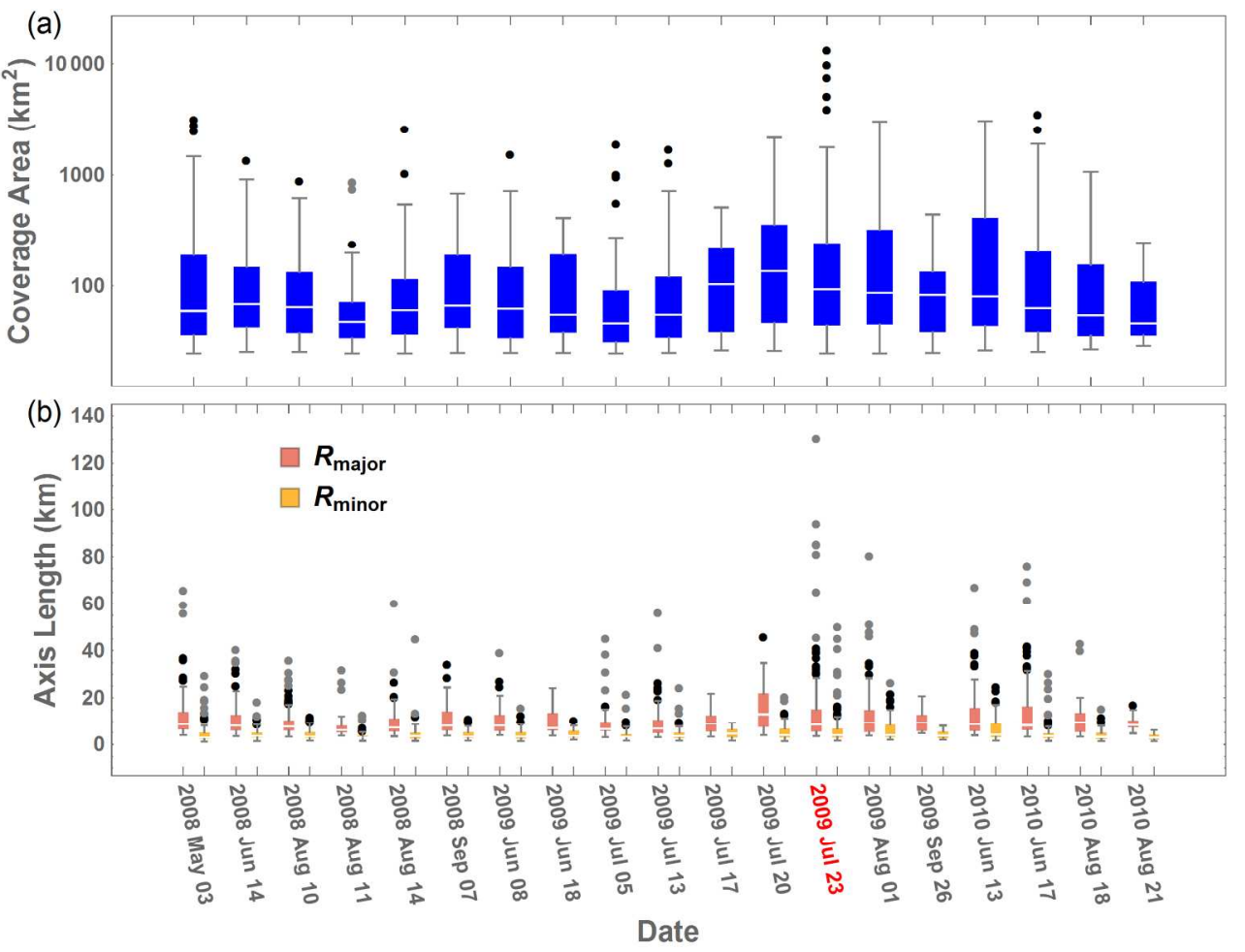

Figure 8 Boxplot of estimated rainstorm features: storm areas (top) and storm radii (bottom), during 19 typical storm events which each contains more than 10 storm cells (The circle represents the outlier values. Each box ranges from the lower 25th quartile to the upper 75th quartile. The median value is denoted by the middle line in the box.).

$211 \times 159 \mathrm{~mm}(300 \times 300 \mathrm{DPI})$ 


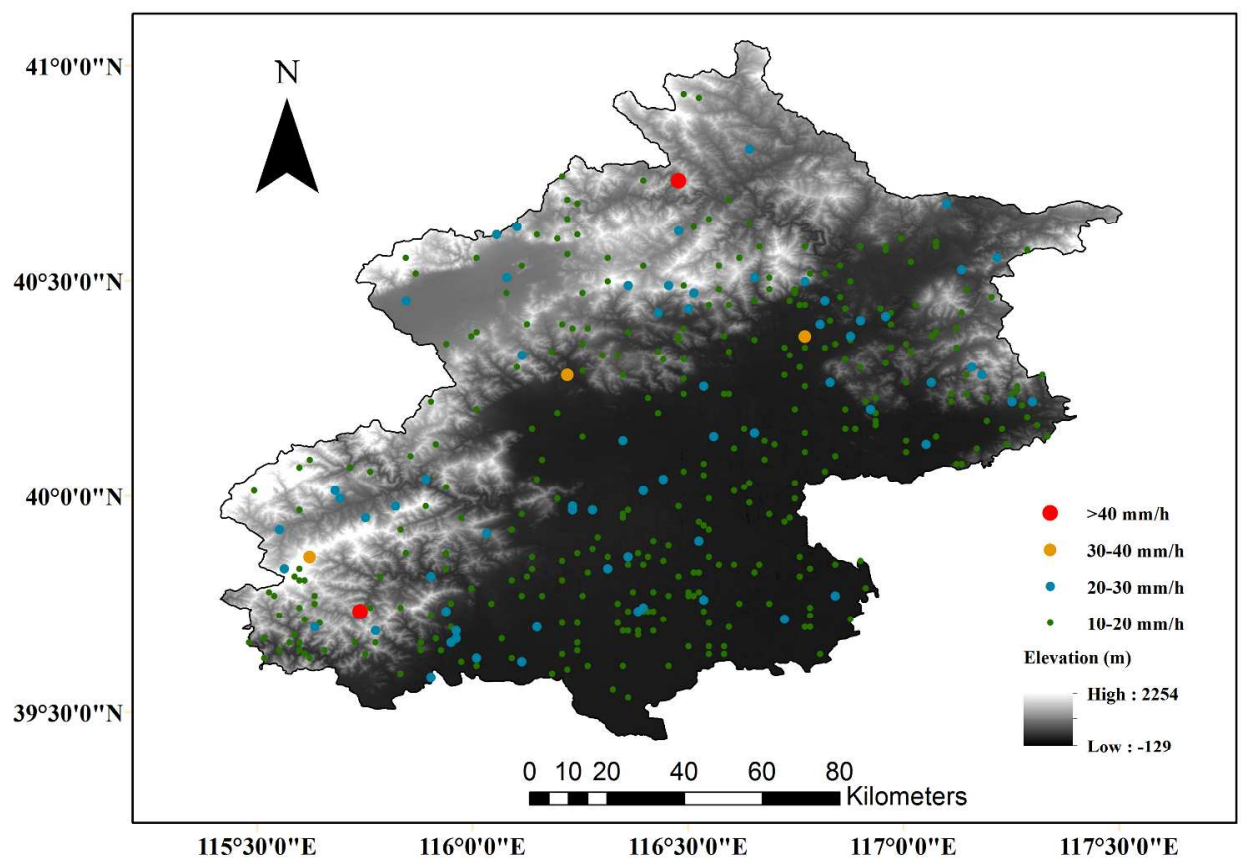

Figure 9 Storm cells locations identified by radar precipitation data from 2008 to 2010 . $297 \times 210 \mathrm{~mm}(300 \times 300$ DPI $)$ 

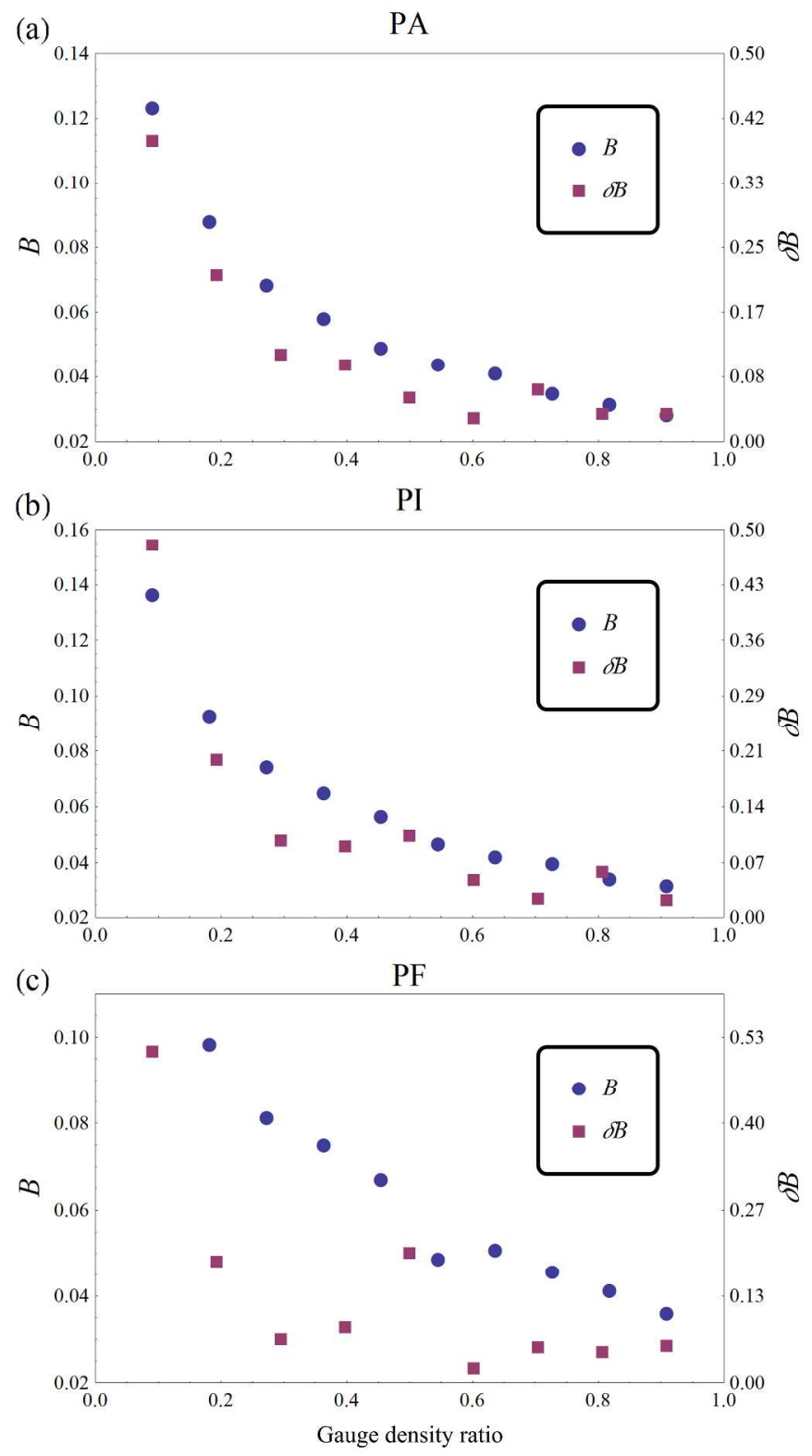

Figure 10 The bias and its corresponding incremental difference of (a) PA, (b) PI and (c) PF with different gauge density ratios.

$256 \times 467 \mathrm{~mm}(300 \times 300$ DPI) 

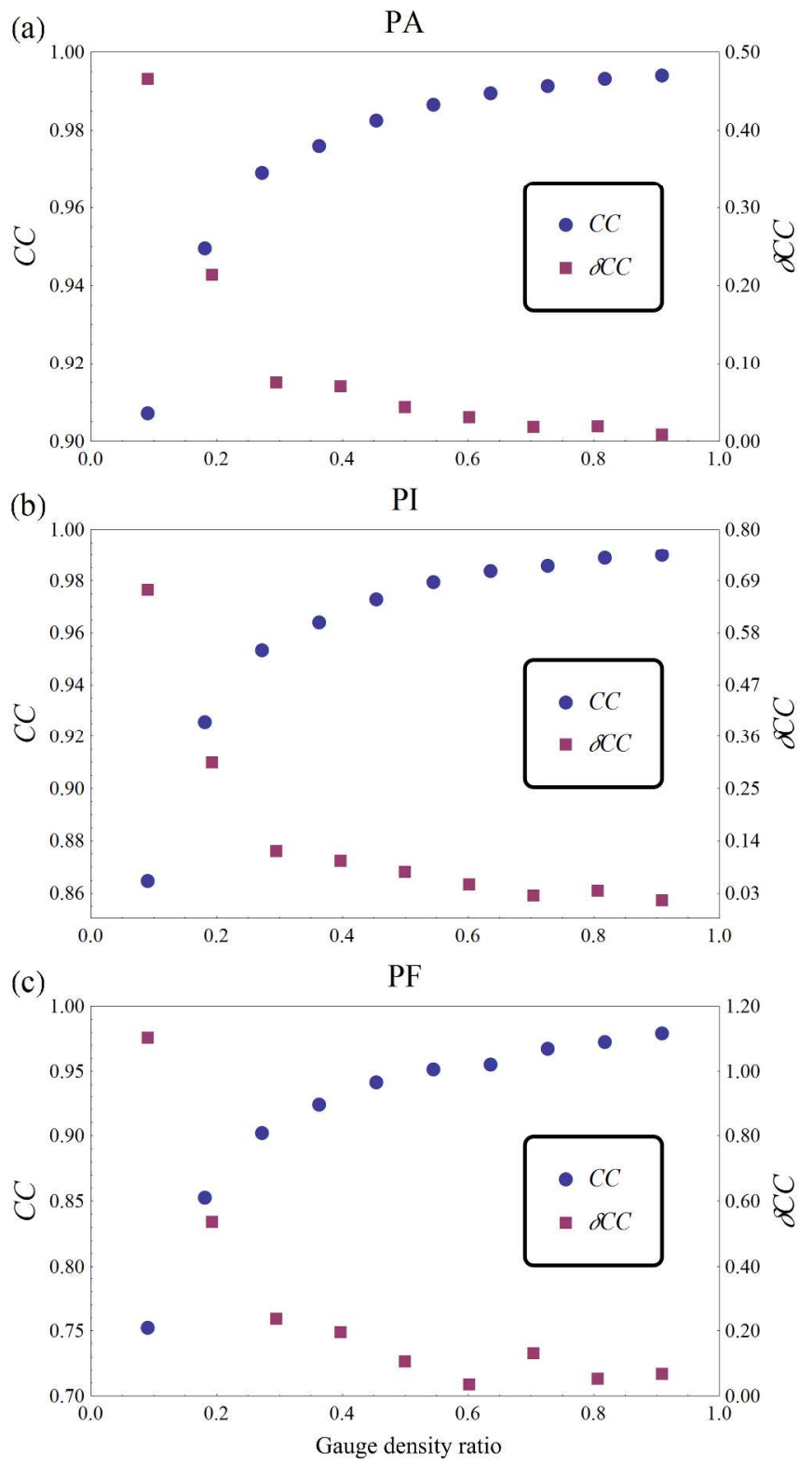

Figure 11 The variations in correlation coefficient and its corresponding incremental difference of (a) PA, (b) $\mathrm{PI}$ and (c) PF with different density ratios. $257 \times 471 \mathrm{~mm}(300 \times 300 \mathrm{DPI})$ 


\section{Tables:}

Tables 1 Summary of storm events during 2008-2010 in the GBR. The storm events were identified with the rain gauge observations as those events with average precipitation of GBR above $20 \mathrm{~mm}$ (* denotes the events without identified rainstorms, and \# denotes the event where radar data is missing. $\boldsymbol{R}_{\text {major }}$, $\boldsymbol{R}_{\text {minor }}$ and Area are given in their mean values.)

\begin{tabular}{|c|c|c|c|c|c|}
\hline Date & Duration (h) & Number of storm cells & $R_{\text {major }}(\mathrm{km})$ & $R_{\text {minor }}(\mathrm{km})$ & Area $\left(\mathrm{km}^{2}\right)$ \\
\hline $2008 / 5 / 3$ & 10 & 53 & 14.97 & 5.80 & 330.91 \\
\hline $2008 / 5 / 11$ & 1 & 1 & 4.31 & 1.85 & 25.00 \\
\hline $2008 / 6 / 14$ & 26 & 53 & 12.48 & 4.98 & 201.29 \\
\hline $2008 / 7 / 4^{*}$ & & & & & \\
\hline $2008 / 7 / 15$ & 6 & 4 & 8.91 & 2.39 & 56.16 \\
\hline \multicolumn{6}{|l|}{$2008 / 7 / 31^{\#}$} \\
\hline $2008 / 8 / 10$ & 24 & 92 & 9.35 & 4.18 & 110.05 \\
\hline $2008 / 8 / 11$ & 19 & 31 & 8.37 & 3.81 & 114.88 \\
\hline $2008 / 8 / 14$ & 11 & 53 & 9.77 & 4.77 & 151.99 \\
\hline $2008 / 9 / 7$ & 12 & 45 & 11.92 & 4.54 & 162.32 \\
\hline $2008 / 9 / 9^{*}$ & & & 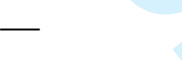 & & \\
\hline $2008 / 9 / 21$ & 4 & 4 & 6.99 & 1.85 & 35.72 \\
\hline $2009 / 4 / 23^{*}$ & & & - & & \\
\hline $2009 / 6 / 8$ & 15 & 34 & 9.21 & 3.76 & 97.28 \\
\hline $2009 / 6 / 18$ & 7 & 7 & 8.77 & 3.12 & 62.95 \\
\hline $2009 / 7 / 5$ & 15 & 46 & 10.17 & 4.47 & 165.13 \\
\hline $2009 / 7 / 13$ & 9 & 50 & 10.59 & 4.84 & 167.75 \\
\hline $2009 / 7 / 17$ & 15 & 28 & 10.94 & 5.24 & 164.75 \\
\hline $2009 / 7 / 20$ & 18 & 50 & 16.76 & 5.75 & 317.37 \\
\hline $2009 / 7 / 23$ & 16 & 34 & 20.58 & 8.77 & 958.83 \\
\hline
\end{tabular}




\begin{tabular}{|c|c|c|c|c|c|}
\hline $2009 / 8 / 1$ & 12 & 35 & 17.50 & 8.03 & 508.46 \\
\hline 2009/8/19 & 3 & 5 & 13.22 & 4.20 & 199.88 \\
\hline $2009 / 9 / 26$ & 7 & 2 & 7.43 & 3.03 & 54.19 \\
\hline $2010 / 5 / 18^{*}$ & & & - & & \\
\hline $2010 / 6 / 13$ & 10 & 23 & 19.57 & 9.10 & 693.76 \\
\hline $2010 / 6 / 17$ & 16 & 41 & 18.62 & 6.73 & 442.64 \\
\hline $2010 / 7 / 9^{*}$ & & & - & & \\
\hline $2010 / 7 / 11^{*}$ & & & - & & \\
\hline $2010 / 8 / 4$ & 5 & 5 & 9.56 & 2.84 & 66.00 \\
\hline $2010 / 8 / 18$ & 12 & 18 & 11.63 & 5.07 & 186.72 \\
\hline $2010 / 8 / 21$ & 9 & 3 & 8.36 & 2.80 & 50.83 \\
\hline $2010 / 9 / 16^{*}$ & & & - & & \\
\hline $2010 / 9 / 18^{*}$ & & & - & & \\
\hline $2010 / 9 / 21$ & 4 & 4 & 6.99 & 1.85 & 35.72 \\
\hline
\end{tabular}


Table 2 Summary of network characteristics of different gauge density ratios

\begin{tabular}{cccc}
\hline $\begin{array}{c}\text { Gauge density } \\
\text { ratio }\end{array}$ & $\begin{array}{c}\text { Number of } \\
\text { gauges }\end{array}$ & $\begin{array}{c}\text { Representative area } \\
\text { per gauge }\left(\mathrm{km}^{2}\right)\end{array}$ & $\begin{array}{c}\text { Incremental difference per } \\
\text { gauge }\left(\mathrm{km}^{2}\right)\end{array}$ \\
\hline 0.1 & 5 & 1437 & -- \\
0.2 & 10 & 718.5 & 718.5 \\
0.3 & 15 & 479 & 239.5 \\
0.4 & 20 & 359.3 & 119.7 \\
0.5 & 25 & 287.4 & 71.9 \\
0.6 & 30 & 239.5 & 47.9 \\
0.7 & 35 & 205.3 & 34.2 \\
0.8 & 40 & 179.6 & 25.7 \\
0.9 & 45 & 159.7 & 19.9 \\
0.99 & 50 & 143.7 & 16 \\
\hline
\end{tabular}

